\title{
CONCEPTUALIZING TRAUMA IN JEWELL PARKER RHODES' TOWERS FALLING: A COGNITIVE APPROACH TO 9/11 TRAUMA METAPHOR
}

\author{
Daban Q. Jaff, Hwma Hiwa and Ahmad Nawzad \\ Koya University, Kurdistan Region, Iraq \\ Email: Daban.jaff@koyauniversity.org
}

Commemoration of the $20^{\text {th }}$ Anniversary of September 11, 2001

Received: June 14, 2021

Accepted: September 15, 2021

\begin{abstract}
This paper discusses the metaphorical representation of trauma stress in Jewell Parker Rhodes' Towers falling (2016) in the light of Stylistics. The study applies insights from the conceptual metaphor theory (CMT) by Lakoff \& Johnson (1980) on selected metaphors from the novel. The analysis finds that the trauma-related metaphors in this novel could be divided into two types. The first one, Deja's personal trauma metaphors, in which source domains like HALLOWEEN MASK, FREEZE, or ROBOT are used. The second one, Pop's trauma stress is expressed by using conceptual structures from source domains of a varied nature, such as STORM, EARTHQUAKE, NIGHTMARE, DYING and WHINE. The analysis found that conceptual metaphors THE BODY IS A CONTAINER FOR EMOTION, and TRAUMA IS A CONTAINER are used to communicate trauma.
\end{abstract}

Keywords: Jewell Parker Rhodes, Towers Falling, Conceptual Metaphor Theory, 9/11 Attacks.

Resumen: Este artículo analiza la representación metafórica del estrés traumático en la obra de Jewell Parker Rhodes Towers Falling (2016) desde un enfoque estilístico. El estudio aplica principios de la Teoría de la Metáfora Conceptual (CMT) de Lakoff \& Johnson (1980) a las metáforas seleccionadas de la novela. El análisis identifica dos tipos de metáforas relacionadas con el trauma. El primero, las metáforas traumáticas de Deja, en las que aparecen dominios Fuente como MÁSCARA DE HALLOWEEN, CONGELAR, o ROBOT. El Segundo, el estrés traumático de Pop es expresado utilizando estructuras conceptuales de dominios Fuente de naturaleza variada, tales como TORMENTA, TERREMOTO, PESADILLA, MORIR y GEMIDO. El estudio concluye que las metáforas que conceptualizan el estrés traumático en la obra en cuestión son EL CUERPO ES UN RECIPIENTE DE EMOCIONES y EL TRAUMA ES UN RECIPIENTE.

Palabras Clave: Jewell Parker Rhodes, Towers Falling, Teoría de la Metáfora Conceptual, Atentados 11-S. 


\section{INTRODUCTION}

After the traumatizing 9/11 attacks took place, many authors, to name few, The Writing on the Wall (2005); Extremely Loud and Incredibly Close (2006); Falling Man (2007); The Memory of Things (2016); attempted to produce a narration to reflect what happened and to show how the comfort of American - especially that of New Yorkers - was disturbed on that day and forth. Jewell Parker's Towers Falling (2016) is one of the narratives about the impact of the 9/11 attacks on New Yorkers. Parker's novel is one of the examples to understand the events of the 9/11 attacks. The novel employs the first-person narrator to tell the story of a fifth-grade student whose name is Deja and her father, Pop. Deja, which is fifteen years after the 9/11 attacks. When Deja begins at a new school, she makes friends with a Muslim girl Sabeen and a boy named Ben whose father is an Iraqi war veteran. The story starts when Deja's teacher asks them to write a paragraph about the $9 / 11$ attacks, she does not know anything about that day and she feels confused. She sets off on a journey of discovery, with Ben and Sabeen by her side. When she gets close to finding an answer to her questions, she uncovers new questions, too, such as: why does Pop get so angry when he hears anything about the Towers? The novel also narrates the story of Deja's father, who works at the World Trade Center Towers. He suffers from a chronic cough, depression, and anxiety, all of which prevent him from maintaining his job. These symptoms are related to trauma stress, in other words, it is trauma stress that prevents him from living a normal live.

The way the 9/11 attacks are represented in literature has been subject of many debates. Different critics attempted to provide a frame for the best form to represent these attacks. At the dawn of the attacks, Don DeLillo, "In the Ruins of the Future" (2001), stresses the importance of evaluating, rather than responding, the 9/11 attacks in literature. In other words, DeLillo, asserts, that fiction should evaluate the psychological impact of the $9 / 11$ attacks, rather than attempting to produce a jingoism or patriotic account. Versluys (2009) believes that the plot of the $9 / 11$ fiction should be mechanical; as the $9 / 11$ fiction is about narrating shattered psyche of people, the narration should not be coherent, but "linguistically diffident" (14), the narration should reflect the psyche of the worn-out traumatized mind. He (2009) also asserts that compensation for the profound symbolic value of the Twin Towers is crucial (14). Richard Gray (2011) and Martin Randall (2014) also discuss the stylistic and thematic aspects of the 9/11 fiction. Both agree, with slight variation, that the 9/11 fiction must avoid localization of the attacks, instead literature should deal with 9/11 as major international events with global influence, and both refute the media rhetoric. Moreover, they assert that the 9/11 fiction need to reflect the unspeakable and silent trauma that American's suffering from.

The studies dedicated to investigating the projection of traumatic experiences of the 9/11 literature takes different approaches; some scholars investigated the ethical and emotional impact of the 9/11 attacks (Versluys 2009, Mauro 2014, Gleich 2014). Others took a psychological approach to examine the impact of the $9 / 11$ attacks on the individuals who were exposed to the $9 / 11$ attacks, and they were aiming at showing why 9/11 traumatic experiences are not absorbable and people cannot speak out their feeling (Huehls 2008, Gray 2011, Pozorski 2014). Few other researches (Jaff and Al-Jumaili 2020, Al-Jumaili and Jaff 2020, Jaff 2020) are employing stylistics models, Conceptual metaphor Theory, to investigate 
how the metaphors are adopted by different writers to communicate traumatic experiences. Díez deploys a thematic and descriptive approach to investigate the role of Jewell Rhodes' Towers Falling (2016), and similar children narrations, in reviving and monumentalizing the 9/11 attacks atrocities in children consciousness (2018). However, Rhodes' novel has not been tackled psychologically nor stylistically. Therefore, this paper adopts a psycho-cognitive approach and it is dedicated to studying trauma-related metaphors in Rhodes' novel.

\section{METHODOLOGY}

The current paper examines the way traumatic experiences in Rhodes' novel are communicated through metaphors. As the model of analysis, the paper benefits from Conceptual metaphor Theory (CMT), which is popularized by George Lakoff and Mark Johnson in their seminal book Metaphors We Live By (1980). CMT claims that metaphor is not language ornament or text beautification, but rather a pervasive, irremovable, and inevitable part of the functionality of the human mind, in other words, metaphors operate on a mental level. CMT claims that metaphor helps people to comprehend one concept - often an abstract concept - in the terms of another - concrete and tangible concept - (Lakoff and Johnson 2008, Kövecses 2009). According to CMT, two domains, conceptual metaphors, are involved in the creation the meaning of metaphors (Steen 2008). "Conceptual domains" are technical terms used by Lakoff and Johnson to refer to mental schematic knowledge and experiences of certain objects or phenomena which are familiar to us - source domain - to elaborate the meaning of an object which is less familiar (target domain) (Lakoff and Johnson 1980). The process of conceptualization occurs when the mind borrows mental correspondence between conceptual elements from the source domain to be applied to the target domain. The process of mental correspondence is called "cross-domain mapping" or "metaphorical mapping" (Lakoff and Johnson 1980). For instance, "you are wasting my time" or "he is investing a lot of time in this project" are two examples of the linguistic manifestation of the conceptual metaphor TIME IS MONEY. The semantic application of these two metaphors is time is money could be spent, lost, gained, etc.

The findings of conceptual metaphor theory have been applied in a variety of fields; In the field of literature, it was applied to analyze metaphors in literary texts such as those that belong to Wordsworth (Steen 1999)It was also applied to analyze the works of Ian McEwan and Harold Pinter (Forceville 1999). Zbikowski applies the knowledge of conceptual mapping to understand how music concepts are understood through concepts from various domains and experiences (2002). This framework has also been used to understand and teach scientific texts, so researchers found that the application of CMT could be useful for teaching and learning topics related to physics, biology, psychology and philosophy and chemistry (Podolefsky and Finkelstein 2006, Beger and Jäkel 2015). On the other hand, Marcel Danesi applies the findings of this framework to teach mathematics (2007).

The current study benefits from cognitive approach to discuss the metaphorical expressions of trauma stress which are used in Rhodes' novel. This cognitive framework helps in identifying the conceptual metaphors involved in the conceptualization of traumatic experiences of her characters. Moreover, this approach is useful in discussing the underlying conceptual structures which are used by the $9 / 11$ victims to construct their own traumatic 
experiences and memories of what they have witnessed on that day. Conceptual metaphors will be introduced in the text with SMALL CAPS; they always come with the order; "target domain is source domain." The following section looks at some selected metaphorical expressions the main characters of the novel who communicated their traumatic experiences metaphorically. The traumatized character is Deja and she also reports the way his father communicates his traumatic experiences through her perception.

Before analyzing the metaphorical representation of trauma in Jewell Rhodes' Towers Falling (2016), it is important to define the term "trauma" which is pervasively referred to in this study. Although trauma could entail physical and psychological injuries, in this paper the psychological trauma, mental wound, belated traumatic emotions and experiences are dealt with. In other words, physical trauma is beyond the scope of this research. The psychological notion of trauma is as old as the pioneering examination of psychological stress. Sigmund Freud is considered to be the first expert to observe psychological stress of survivors of railway victims (Freud 1920). Here, Caruth's definition of literary representation of trauma is adopted. In Unclaimed Experience (1996), Caruth characterizes trauma as "a mind-boggling experience of unexpected or disastrous occasions wherein the reaction to the occasion happens in the regularly postponed, uncontrolled dull appearance of pipedreams and other meddling marvels"'(11). In contrast to actual and physical injuries, which for the most part are healable, the psychological injury is unpleasant and most times is not healable.

Throughout history, different terminologies have been given to trauma: "shell shock, combat neurosis, or traumatic neurosis" (Caruth 1996: 130). In the eighties of the previous century, American Psychiatric Association (hereinafter APA) unifies these overwhelming terminologies to Post Traumatic Stress Disorder (PTSD. APA asserts that "directly experiencing the traumatic event(s), witnessing in person, the event(s) as it occurred to others experiencing repeated or extreme exposure to aversive details of the traumatic event(s)" are generating trauma stress (APA 2013: 271).

On the other hand, Dominick LaCapra studied representation of trauma in literary texts. He describes trauma as "disruptive experience that disarticulated the self and creates holes in existence; it has belated effects that are controlled only with difficulty and perhaps never fully mastered" (2010: 41). Moreover, LaCapra, coins "acting out" and "working through" to distinguish between experiencing trauma and producing a narrating traumatizing story. According to LaCapra (2014), "acting out" is the trauma phase in which the traumatized person remembers what happened on traumatizing day and loses he/she must endure and the amount of the destruction of traumatizing attacks causes. On the other hand, "working through", LaCapra (2014) stresses, is second phase of trauma. In this phase, a traumatized individual is able to produce a structured account of the traumatizing days (2014: 148). However, trauma victims are reluctant to tell their stories (Caruth 1995). Even if traumatized people try to narrate their traumatizing stories, describing the trauma-related complex feelings and emotions literally is considered a daunting task, therefore, traumatized people attempt to employ metaphors to communicate their trauma-related feelings and emotions (McLean and Woody 2001, Wilson and Lindy 2013, Quinn 2020).

Here, the above definitions and characteristics of the psychological state of trauma are dealt with. People are experiencing different symptoms of trauma and could experience a range of trauma symptoms; they vary according to individuals. Expressing traumatic 
experiences literally is extremely difficult. Therefore, scholars (Ortony and Fainsilber 1987, Junghaenel, Smyth and Santner 2008, Emanatian 2009) found that figurative language could be aiding traumatized people to compare the enormity of their abstract notion of traumatic stress to more familiar objects, in other words, metaphors could be very useful in expressing traumatic experiences of traumatized individuals. This paper is dedicated to investigating the representation of traumatic experiences through metaphors. The paper aims at investigating the donated structures of the source domain which are elaborating the meaning and the scale of trauma experiences by different characters in the novel. For space and time limitations, only selected metaphors of the main characters will be analyzed. The analysis starts with metaphors of Deja. The paper concluded with analyzing the metaphors of Pop, and Deja.

\section{ANALYSIS}

Deja is a girl of 10 who lives with her parents and two siblings in the Avalon family shelter. She is the eldest child and is often responsible for her brother and sister since her father is unable to do so. Her mother struggles to support the family financially. Deja is placed in a role that is way beyond her capacity. When Ma, Deja's mother, is at work, she is in control. Pop is unable to assist with any of the household tasks, but she and Ma are responsible for it. Deja despises her family's lifestyle. Pop, on the other hand, is the second main character in the novel. He suffers from a severe headache and lays in bed. He does not take responsibility for the family and does not do anything. He is almost paralyzed. At first, Deja is very angry and sad about her father for not doing anything like helping Ma with any tasks of the household, but after she sets off on a journey of discovery about the 9/11 attacks, she realizes that her father, Pop, is the hero of the day of the event like he rescues his manager and many other peoples when the towers fell; "I want to fall on the bed and cry and cry. I never should've been angry at Pop" (Parker 2016: 207).

The first representation of a traumatic experience as a metaphorical expression occurs when Deja is complaining about her life and how she takes everyone's responsibility. She states that "I'm the oldest. I have got to be responsible and I hate that" (2016: 6). She complains about her life, she also mentions her father Pop and how broken and unable he is due to the catastrophic incidence of 9\11 which severely affected his mental state. She describes her father's condition as being alienated and unsocial, she says that "After his bad dreams, he stands on the street corners. Doesn't talk with other out-of-work men. He freezes as no one else exists" (Parker 2016: 6). In this extract, the lexical item "Froze" is used against its literal sense. According to Oxford Online Dictionary, "Froze" is defined as "to become hard, and often turn to ice, as a result of extreme cold; to make something do this" (2021). But in the context of the novel, "froze" is used to refer to the mental and physical condition of Pop. In other words, Pop lost track of being socially interactive.

Pop, Deja's father, used to be a happy and normal father, but due to being exposed to 9/11 traumatic attacks, he has changed. In one extract, Deja describes his father as "I can tell she thinks we're acting like a real family again. Pop is the before Pop, happy, playing with us. It's extra sweet Ma bought chicken so we don't have to eat in the gross cafeteria" (2016: 45). According to many scholars, initial responses to trauma include exhaustion, numbness, confusion, and dissociation, while more severe reactions include constant distress without 
periods of relative calm or comfort (U. S. D. health and human services 2016; Bremner and Marmar 2002: 57). These symptoms apply to Pop. Pop's memories are impeding him from moving and thinking normally. In addition, Deja says that Pop does not talk with any of his workmates and prefers to avoid others. Avoidance often co-occurs with anxiety. When the anxiety develops over time, and the perception that the situation is unbearable, increases the chances of leading to a greater need to avoid what is happening around (U. S. Department of health and human services 2016). She also added: "when his headaches fiercely, he has to lie down and no one is allowed even to whisper or move" (Parker 2016: 6 ). Therefore, Pop is traumatized by the $9 / 11$ attacks and he shows the symptoms of trauma stress physically and mentally.

Therefore, comparing the literal meaning with the contextual meaning indicates that the verb 'freeze' is used as a metaphorical representation to stand for an abstract quality which is Pop's traumatic stress. As far as the conceptual domains are concerned, the verb "froze" is a source domain from which conceptual structures such as getting very cold, changing onto the ice, and lifelessness are mapped from the source domain of 'freeze' into the target domain of trauma. As a result of the cross-domain mapping, the target domain is getting a newly formed meaning which is Pop's mental illness is seen as a disability, and the terrifying memories that are stored inside his head prevent him from regularly responding and moving. Moreover, Pop's trauma stress is turning his mind into ice, preventing it from its basic and primary functions. The metaphorical expression of Pop's traumatic incidence is the linguistic realization derived from the conceptual domain such as SADNESS IS A LACK OF VITALITY (Kövecses 2005: 25), SAD IS HEAVY (Yu 1998: 255; Kovecses 2005: 101), SADNESS IS ILLNESS (Kövecses 2000: 26).

The second metaphorical expression of Pop's traumatic experience is stated when Deja was asked, by her teacher Miss Gracia, to write a paragraph about her home as well as the "missing towers" (Parker 2016: 45). When Deja mentioned the towers, her father's hand "starts shaking" (Parker 2016: 45) due to the horrible memories that he remembered on that day. Deja describes how her father " face looks like a scary Halloween mask" (Parker 2016: 45). The facial expression of Pop's traumatic experience in this extract is conceptualized in terms of "Halloween mask". Our prior understanding of Pop's psychological and mental state condition informs us that he experienced and witnessed the atrocities of 9/11 attacks first hand., and his mind still brings back negative memories making him feel anxious which leads him to have an intense emotional reaction: "See, Dèja, I don't exactly know what happened. But I imagine. Imagining makes my headaches explode" (Parker 2016: 201).

The adjective phrase "Halloween mask" is used in a metaphorical sense rather than a literal one to refer to behavioral disorders as excessive fear and anxiety of Pop's traumatic experience. The trauma-stress victims suffer from a traumatizing incident, resisting to talk about what happened to them or to talk about their feelings because they went through a severe experience and overwhelming feelings in the course of trauma (Allen 1999: 50). Moreover, Deja also states that her father's hand "starts shaking and his face crumbles" these symptoms trigger when Deja mentions the towers, which could be interpreted as, and according to APA guidelines, trauma stress symptoms and an indication of the fact that 9/11 attacks have an extreme impact on the victim's mind and behavioral condition. 
These symptoms are activated by hearing the adjective phrase "missing towers" which are flashbacks of recurring 9/11 attacks (APA 2013: 271).

Stylistically, "Halloween mask" is a source domain that provides conceptual structures for elaborating the meaning of the target domain of traumatic stress. The adjective phrase "scary Halloween" activates many scenarios: frightening, creepy, obscure, disguise, and ghost. The conceptual structures mapped, pave the way to understanding the target domain of trauma clearly. Through cross-domain mapping, trauma is understood as frightening, creepy, obscure, and ghost-ish-like experiences. Another scenario is triggered by a lexical item "mask". In this metaphor, "mask" provides more psychological conceptual structures such as disguises and impersonating different personalities. Through the analogy, we understand that victims of trauma are hiding their real identity, instead, they have to cope with the post-trauma era, in other words, trauma victims are alienated and wearing different masks on different occasion (Schauer, Schauer and Elbert 2005: 1, Reyes, Elhai and Ford 2008: 24). "Halloween mask" is a linguistic realization activated by conceptual domains of NEGATIVE EMOTION IS DARK (Barcelona 2012: 47) and NEGATIVE EMOTION IS DISGUISE.

The third metaphorical representation of traumatic experience occurs when Deja, Sabeen, and Ben are watching the recorded video of the catastrophic incidents of the falling towers. Deja is describing the collapsing of the two towers as "particles of glass and concrete flurry like a tornado" (Parker 2016: 146) when "tons of gray smoke darkening the sky" (Parker 2016: 146) these are resembling the traumatic experience of Deja and her. In this context "tornado" is used against its prototypical sense. According to the forecast reports, 9/11 day was a nice shining day, there was no sign of a tornado or any other harsh weather conditions. The writer is alluding to a natural disaster to show how the horrible and frightening view are traumatizing Deja's mental state. Metaphorically speaking, Deja's traumatic experience leads her to exaggerate in her description of the catastrophic incidence because such negative modifications in cognition and condition are associated with the traumatic event according to APA guidelines. A sudden, terrifying, and overwhelming event - like the falling of the towers - can cause an unexpected reaction; difficulty concentrating and difficulty making decisions (APA 2013: 271). Therefore, comparing and contrasting the contextual meaning with the metaphorical one, shows that the noun "tornado" has been used metaphorically rather than literally, it stands for a conceptual quality which is Deja's traumatic experience.

Stylistically, the source domain "tornado" aids Deja with conceptual structures to interpret the target domain of traumatic stress. As a result of the cross-domain mapping, the conceptual structures such as fire, natural force, physical damage, and destruction are mapped from the source domain of "tornado" onto the target domain of trauma. As a result of this cross-domain mapping, the target domain acquired a different and newly constructed meaning which is Deja's traumatic experience is communicated through the destructions followed by the natural force of a tornado. Through the metaphor, trauma stress is depicted as a natural force that leaves a devastating impact on the mind of the trauma victims. Moreover, Deja's mind is depicted as a location that is subjected to destructive occurrences of natural forces like tornadoes. This metaphorical expression of a "tornado" is the linguistic realization of the conceptual metaphors of EMOTION IS A NATURAL FORCE, NEGATIVE EMOTION IS DOWN (Forceville 2008: 476), STATES ARE LOCATIONS (Gibbs 2005: 9), SADNESS IS A NATURAL FORCE (Kövecses 2000: 25). 
Another two metaphorical expressions of traumatic experiences occur when Ben, Sabeen, and Deja, are watching the captions of the 9/11 attacks. While they are eating their lunch, Deja says that her father Pop "has survived 9/11" (Parker 2016: 147).Ben and Sabeen are shocked. Deja wants to watch the video again to know exactly what happened to her father. They watch the video and Deja feels very sick and cries when she sees what happened on that day. She askes Ben how long it took? He replies, "the North Tower collapsed twenty-nine minutes after the South Tower" (Parker 2016: 147), Deja describes Ben's response as he "sounds like a robot, dull and factual" (Parker 2016: 147). In this extract "robot" is used in a metaphorical sense, because "robot" is used to modify the reaction of Ben when he hears what has happened to Deja's father. The noun "robot" is a metaphorical description of Ben's psychological response to the video, because human beings cannot have the features of robots since robots are machines that can move and do some work, and they are controlled by computers (Longman 2021). Moreover, robots are senseless and cannot express any sort of emotion, and socially they are not interactive.

According to scholars, trauma stress victims tend to compress and encompass their strong emotions, and some others reject any sort of expressions but stay in numbness and lack vividness (U. S. Department of health and human services, 2016; LaCapra 2014). Comparing the literal meaning with the contextual usage indicates that the noun 'robot' is a metaphorical representation used to modify the abstract state of traumatic stress. As far as the conceptual domains are concerned, the noun "robot" is the source domain. The source domain "robot" donates conceptual structures such as senselessness, devoid of spirit, lack of emotions to be mapped onto the target domain of traumatic stress. As the result of the cross-domain mapping, the target domain of trauma is acquiring new meanings such as when trauma stress strikes, the victim of trauma will be socially detached and get disconnected with their sounding, trauma stress prevents traumatized people from vividness and they will be locked in senseless bars of trauma. The noun 'robot' is a linguistic realization based on conceptual domains such as SADNESS IS LACK OF MOTION (Kövecses 2012: 175), SADNESS IS A LACK OF VITALITY (Kövecses 2005: 25).

Another example of the metaphorical expression of Deja's traumatic experience occurs on page (195) when Pop decides to talk about the 9/11 attacks to his daughter for the first time. Deja can feel his stress when she states that "Pop's being kind, but underneath his skin, I sense his stress, a low panic in his muscles and bones" (Parker 2016: 195). Deja expresses her feelings through "the room is getting smaller" (Parker 2016: 195) when she states that "I can't breathe right. feels like the room is getting smaller, there's no window to remind me there's air outside" (Parker 2016: 195). The expression "the room is getting smaller" is used in a metaphorical sense because, literally, rooms cannot expand or tighten. In addition to that, this expression occurs when Pop is talking about escaping brutal death which traumatizes both Pop and his daughter. In addition to that, Deja illustrates the gravity and intensity of the atmosphere during the conversation that takes place between her and her father.

According to APA guidelines, among the traumatic symptoms and reactions associated with the traumatic event is an exaggerated response to the incidence. It is claimed that among trauma's symptoms is "inability to express positive emotions, like happiness and satisfaction" (APA 2013: 272). In addition to that, Vaile Wright, Collinsworth, Fitzgerald (2010) believe that trauma disrupts the schematic knowledge of its victims (1807). In other 
words, the natural schematic knowledge of trauma victims is dislocated, trauma victims find it difficult to relate, trauma victims cannot make sense, moreover, articulating logical understanding is challenging for trauma victims (The International Society for Traumatic Stress Studies 2016: 3). Therefore, comparing the literal meaning with the contextual usage suggests that the noun phrase "the room is getting smaller" is used metaphorically to stand for a negative mental state as an abstract quality. The abstract quality is Deja's traumatic feeling of her negative mental state which is making her think incoherently as if the room is closing its walls on her.

Stylistically, in this metaphor the source domain is invisible. Identifying one lexical item in this expression "the room is getting smaller" is not feasible. Invisible metaphor is occurring when a lexical item could not be identified as the domain which donates conceptual structures to modify the target domain of trauma (Stockwell 2002: 107). Therefore, the whole chunk is providing conceptual structures to modify the meaning of the target domain of traumatic stress. As the result of the cross-domain mapping, the trauma notion acquired new features which are mapped from the source domain of "the room is getting smaller". The mapping frames are increasing the understandability of traumatic stress. Through the analogy, trauma stress is squeezing the mind and disturbs its coherent perception of what is happening around the victims of traumatic stress. This metaphor is a projection of the impact of trauma on Deja's mind. Through the metaphor, Deja's mind is depicted as a body that is expanding and tightening when trauma stress strikes, this scenario is activated by "feels like" which occurs before the metaphors. The linguistic expression of "the room is getting smaller" is based on the conceptual metaphors EMOTION IS PRESSURE INSIDE A CONTAINER (Kövecses 2003: 65), THE BODY IS A CONTAINER FOR EMOTION (Kövecses 2010: 171) and TRAUMA IS A CONTAINER (Downing 2018: 200).

Another representation of the traumatic anxiety occurs when Deja is describing his father's expression. In that context, Pop talks about the 9/11 day. Pop tells Deja that he was there when the buildings "swayed in fierce winds" (Parker 2016: 199). While Pop is talking about a catastrophic accident, Deja grasps her father's facial expression and describes it like "His face looks like he's waking from a nightmare" (Parker 2016: 199). Since nightmares only can occur while someone is sleeping, in this context lexical item "nightmare" is used metaphorically to describe the terrorized facial expression of HER father. Researchers believe that one of the many symptoms of PTSD on the survivors is 'flashbacks' when they lose control of the current situation and react as if the traumatic event is occurring again (Rathbaum and Rauch 2020: 77). Moreover, recurrent and intrusive constructions of what happened on the traumatizing days are also considered as the symptom of trauma stress (APA 2013: 271). This applies to Pop in which his negative memories return to him leading to uncontrollable reactions. Pop saw the accidents with his own eyes, these brutal scenes, of course, were attributed to the aftermath of the traumatic incident.

Therefore, comparing the literal meaning with the contextual usage implies that the noun "nightmare" is used metaphorically in the given extract to stand for an abstract quality of traumatic stress. As far as conceptual domains are concerned, the noun "nightmare" can be qualified as a source domain from which selected conceptual structures such as fear, horror, and negative memories are mapped onto the target domain of trauma. As a result of the cross-domain mapping, these conceptual frames from the source domain of "nightmare" 
provide a new meaning for the abstract state of trauma. Through the metaphor, trauma stress is given the qualities of a nightmare. In addition to depicting trauma stress as being in a scary dark place, trauma stress is also understood as a terrorizing, horrifying, and devastating mental faculty. In creating this analogy between both domains, the conceptual metaphors which underpin the speaker's linguistic expression are SAD IS DARK, SADNESS IS DARKNESS and EMOTION IS DARK (Kövecses 2000: 25-27).

Another traumatic experience as a metaphorical expression occurs when Pop is going into a sympathetic, emotional and thoughtful conversation with her daughter, Deja, about the 9/11 attacks. Pop defines his mental health as an "explosion" to show his negative emotional experience as a traumatic expression. He reaches a state of depression that even thinking makes him sick. "See, Dèja, I don’t exactly know what happened. But I imagine. Imagining makes my head ache, explode" (Parker 2016: 200-201). In this context, "explode" is used in a metaphorical sense. Oxford Online Dictionary defines "explode" as "to burst (break apart) or make something burst loudly and violently, causing damage" (2021). This definition does not indicate that the human body or organs can explode or burst spontaneously. Therefore, the word "explode" is used metaphorically to refer to the mental condition of Pop. It is used to describe what trauma stress, memories of that day, has done to Pop's mind.

Psychologically, Pop is overthinking, he is not able to overcome his trauma stress and forget what happened on that day, in another context, he says that "I still see, feel, hear, smell every last bit of it. When I close my eyes. When I sleep and dream" (Parker 2014: 200). In this quotation, Pop confesses that he is still under the impact of severe memories of the 9/11 attacks. Psychiatric scholars believe that trauma victims are suffering from severe symptoms like "difficulty of sleeping, lack of controlling things and, having chronic tension headaches" (Bennis 2020: 201), and trauma pushes on their minds and they also report that they are imagining that their head is exploding under the trauma stress pressure. Hence, comparing the literal meaning with the contextual usage suggests that the verb "explode" is used metaphorically rather than literally to stand for Pop's traumatic experience which impedes him from thinking logically and coherently.

As far as the conceptual mapping is concerned, the source domain of the concept "explode" provides conceptual structures to the target domain of trauma stress. The crossdomain mapping between domains resulted in donating structures such as breaking up into pieces violently and bursting from the source domain of the "explode" onto the target domain of the abstract state of the traumatic stress. As a result of the cross domain-mapping, the target domain is acquiring newly constructed meaning. Through the metaphor, Pop's body is depicted as a container that is pressed by trauma to a degree that the container is no longer able to keep it together, but it is exploding. In other words, when trauma strikes, Pop's body is on the verge of explosion. The metaphorical expression, 'head exploding' is the linguistic realization derived from the conceptual metaphors of EMOTION IS PRESSURE INSIDE A CONTAINER (Kövecses 2003: 65). THE BODY IS A CONTAINER FOR EMOTION (Kövecses 2010: 171) and TRAUMA IS A CONTAINER (Downing 2018: 200).

Towards the end of the novel, another two metaphorical expressions materialise/ take contour. The metaphor is stated when Pop narrates the early moments of the attacks. He witnessed the death of his fellow friends. He describes the impact of the explosion on the tower to "whine" and "earthquake" in "The building whined. Inside it felt like there was an 
earthquake shaking the foundation, the walls, windows, and ceiling" (Parker 2016: 203). In this context, there are two metaphorical representations of the trauma stress; "building whined," and "the tower was dying." In these two extracts, the towers are personified through "whine" and "dying", because whining and dying are living creatures features, non-living objects cannot die or whine. These two metaphors are manifestations of the much-disturbed mental condition of Pop. Through these metaphors, readers realize that Pop is devastated and dominated by trauma stress.

By the end of the novel, Pop shows some signs of starting the journey of recovering from trauma stress. According to LaCapra (2001), the "working though" phase is the starting point of recovering from trauma stress, he also asserts that victim who is suffering from trauma stress "requires going back to problems, working them over, and perhaps transforming the understanding of them" into narration (148). Pop starts to narrate what he has witnessed, he says that "Mrs. Able from the accounting firm on the thirty-seventh floor fell against me" he also shows sympathy towards his fellow victims as he imagines what Mrs. Able is saying; "James, I can't move. Too scared. Help me down, James. Help an old lady down" (Parker 2016: 203). Pop's statement is evidence that Pop is traumatized twice; first he is traumatized by the attacks and he also suffers from "survival guilt". Psychological studies assert that people who are able to escape death imposed by traumatizing attacks develop “survivor's guilt" (Murray 2019: 600).

The description of the building shows the frightful view and the perplexed mental state of Pop which resembled through the "whining" sound that expresses Pop's traumatic experience. In this metaphor, the building is personified and given the qualities of a human. Therefore, comparing and contrasting the literal meaning with the contextual expression suggests that the noun phrase "the building whined" is a metaphorical expression used to stand for an abstract quality. The abstract quality is Pop's traumatic experience that affects his mental health and makes him think irrationally. The phrase "building whined" is a source domain from which conceptual structures such as panic, horror, and physical harm are mapped from the source domain into the target domain of traumatic experience of Pop. Through the cross-domain mapping, the target domain of trauma acquires a new meaning; trauma stress is causing panic, horror, and physical harm when it strikes. The linguistic metaphor "whine" is activated by the conceptual metaphor SADNESS IS DOWN (Barcelona 2012: 33), EMOTION IS PHYSICAL OBJECTS (Yu 2008: 254).

Another metaphorical portrayal of a traumatic event occurs on the same page. Pop describes his feelings when the attacks are carried out as "it felt like an earthquake shaking the foundation, the walls, windows, and the ceiling" (Parker 2016: 203). In this context, "earthquake" is used metaphorically in the early moments of the attacks. The contextual view of the traumatic experience is conceptualized as an 'earthquake'. Some psychological researchers reported that traumatic stress experiences might be revealed via many natural disasters like tsunami, earthquakes, and hurricanes (Lee, Kim \& Kim 2020). Conceptual structures such as destruction, annihilation, violent shaking are mapped from the source domain of 'earthquake' into the target domain of trauma. As a result of the cross-domain mapping, the target domain can now acquire a new meaning; trauma is seen as a destructive natural force. The linguistic realization of the metaphorical expression is derived from the 
conceptual domain EMOTION IS ANATURAL FORCE, NEGATIVE EMOTION IS DOWN (Forceville 2008: 476) and SADNESS IS A NATURAL FORCE (Kövecses 2000: 25).

The metaphor extends to the other similar personification "the tower was dying". Conceptual structures such as death, fear, and falling off, are mapped from the source domain of "dying" onto the target domain of trauma. As a result of the cross-domain mapping, the target domain of trauma acquired a newly constructed meaning. Trauma stress is depicted as an entity that can kill and knock down the victim of the trauma, mentally and many times physically. The metaphorical expression is the linguistic realization that is derived from the conceptual domain such as SADNESS IS DOWN (Barcelona 2012: 33) and NEGATIVE EMOTION IS DOWN (Forceville 2008: 476).

Towards the end of the novel, another metaphorical representation of trauma stress occurs when Deja and her father are discussing the day of the catastrophic 9/11 attacks. Pop narrates what he has experienced during that day and compares it to another natural force, he states that "there was a silence before the worst hit, before the storm" (Parker 2016: 204). In this extract, "storm" is used against its literal meaning. As it has been shown before, the 9/11 day was a clear and beautiful day and there was no indication of any sort of weather disturbance. However, Pop compares the attacks to storms. As it has been shown in previous metaphors, this metaphor is also an indication of Pop's disturbed psyche. In addition to that, Pop, through comparing what happened, is trying to give the reader, and his daughter, a clear and transparent vision of the enormity of the attacks. Therefore, comparing the literal meaning with the contextual usage suggests that the noun phrase "the storm" is a metaphorical expression borrowed to express an abstract quality. The abstract quality is Pop's traumatic experience that affects his mental health and prevents him from thinking coherently.

Regarding conceptual domains, the cross-domain mapping is conducted between the source domain of "the storm" and the target domain of traumatic stress. The source domain of "storm" donates many conceptual structures. The newly constructed meanings of target domain of trauma stress can now be defined as explosion, shock wave, blast, and terror. Through the cross-domain mapping, trauma stress is depicted as a natural force with immense power. Through the process of the cross-domain of the two different domains, Pop's trauma can now be understood in terms of "the storm". This metaphorical expression, "the storm", is the linguistic realization of the conceptual metaphors of EMOTION IS A NATURAL FORCE, EMOTION IS A PHYSICAL FORCE and SADNESS IS A NATURAL FORCE (Kövecses 2000).

\section{CONCLUSION}

In conclusion, the current paper has discussed some trauma-related metaphorical expressions in Jewell Parker Rhodes Towers Falling which are stated by Deja, the narrator, and metaphors of Pop, Deja's father. The paper briefly examined the way metaphorical expressions can communicate an abstract state of traumatic stress. The analysis found that, since communicating mental state is difficult to express literally, metaphors are an effective linguistic and cognitive vehicle to aid characters to communicate their negative mental state of trauma stress. In Rhodes' novel various conceptual domains are involved in the creation of the discourse of trauma. The analysis found that the trauma-related metaphors in this 
novel could be divided into two types; first, personal related trauma metaphors, through which personal experiences of Deja are communicated. In the first type, conceptual structure of the source domains like "Halloween mask", "freeze", "robot" and "the room getting smaller", in addition, in one occasion, Deja is using the conceptual structure of a natural force phenomena " tornado" to elaborate the meaning of traumatic stress. The Second, Pop's trauma-related metaphors in which he describes the enormity of the attacks. Pop uses conceptual structures from source domains of different natural forces to modify the meaning of trauma stress, such as "storm", "earthquake", "storm", in addition, Pop relies on other sources domains such as "nightmare", "dying" and "whine" to modify the meaning of traumatic stress. Moreover, the analysis found that conceptual metaphors EMOTION IS PRESSURE INSIDE A CONTAINER, THE BODY IS A CONTAINER FOR EMOTION, and TRAUMA IS A CONTAINER are used to communicate trauma stress. The analysis also found that the cognitive approach adopted by this study has proven to be a useful tool to understand the metaphorical representation of traumatic stress in the novel. Since the novel is narrated in the first-person narrator, almost all metaphorical representations of trauma have been stated to represent Deja they represent her father's trauma through Deja's perceptions. As a result of applying CMT, it becomes possible to see such abstract notions like trauma in a more concrete, tangible way.

\section{REFERENCES}

Al-Jumaili, Y. \& JAFF, D. 2020. “Conceptualizing Trauma in Jonathan Safran Foer's "Extremely Loud and Incredibly Close": A Cognitive Approach." The International Journal of Communication and Linguistic Studies, 18,2: 1-15.

Allen, J. 1999. Coping with Trauma: A Guide to Self-understanding. Washington, DC: American Psychiatric Press.

American Psychiatric Association. 2013. Diagnostic and Statistical Manual of Mental Disorders. 5th ed. Washington, DC: American Psychiatric Association.

BarcelonA, A. 2003. "On the Tlausibility of Claiming a Metonymic Motivation for conceptual metaphor." Metaphor and Metonymy at the Crossroads, 31:18, 31-58.

BEGER, A. \& JãEKEL, O. 2015. “The Cognitive Role of Metaphor in Teaching Science: Examples from Physics, Chemistry, Biology, Psychology and Philosophy." Philosophical Inquiries, [online] 3:1, 89-112. https://philinq.it/index.php/philinq/article/view/116.

Bremner, J. \& Marmar, C. 2002. Trauma, Memory, and Dissociation. Erscheinungsort Nicht Ermittelbar: American Psychiatric Press Inc.

Bush, E. 2016. "Towers Falling by Jewell Parker Rhodes.” Bulletin of the Center for Children's Books, 69:10, 542-542.

CARUth, C. 1995. Trauma: Explorations in memory. Baltimore: Johns Hopkins University Press.

CARUTH, C. 1996. Unclaimed Experience: Trauma, narrative, and History. Baltimore: Johns Hopkins University Press. 
DANESI, M. 2007. "A conceptual metaphor framework for the teaching of mathematics." Studies in Philosophy and Education, 26:3, 225-236.

Delillo, D. 2001. "In the Ruins of the Future, By Don DeLillo". Harper's Magazine. Accessed 11 Jun. 2021. https://harpers.org/archive/2001/12/in-the-ruins-of-the-future/.

Delillo, D. 2007. Falling Man: A Novel. London: Picador.

DíEz, M. 2018. "Translation and adaptation of terror: Two books for children and teenagers on $9 / 1115^{\text {th }}$ anniversary". Anuario de investigación en literatura infantil y juvenil: ANILIJ, 16, 131-140.

DownING, L.H. 2018. "Metaphoric interpretations of a short story by J.D. Salinger: A reader response study." In Rethinking Language, Text and Context. Interdisciplinary Research in Stylistics in Honour of Michael Toolan. R. Page, B. Busse \& N. Nørgaard, Eds. New York: Routledge. 191-207.

Emanatian, M. 1995. Metaphor and the Expression of Emotion: The Value of Cross-Cultural Perspectives. Metaphor and Symbolic Activity, 10, 3: 163-182.

FABRIZIO, L. 2020. "Speaking Out: Art Therapy for Trauma, Eating Disorders, and Substance Use Disorders." In A. Quinn, Ed. Art Therapy in the Treatment of Addiction and Trauma. London: Jessica Kingsley Publishers. 153-173.

FOER, J. 2005. Extremely loud \& incredibly close. Boston: Houghton Mifflin Harcourt.

ForCEVILle, C. 1999. “The Metaphor “Colin Is A Child” in Ian McEwan's, Harold Pinter's, and Paul Schrader's The Comfort of Strangers." Metaphor and Symbol, 14, 3: 179-198.

ForCeVILle, C. 2008. "Metaphor in pictures and multimodal representations." In The Cambridge Handbook of Metaphor and Thought. R.W. Gibbs Ed. Cambridge University Press. 462-282.

GIBBS, JR. R. 2006. “Cognitive linguistics and metaphor research: past successes, skeptical questions, future challenges." DELTA: Documentação de Estudos em Lingüística Teórica e Aplicada, 22, 1-20.

GLeich, L. 2014. "Ethics in the Wake of the Image: The Post-9/11 Fiction of DeLillo, Auster, and Foer." Journal of Modern Literature, 37, 3: 161-176. DOI:10.2979/ jmodelite.37.3.161.

GraY, R. 2011. After the Fall: American Literature since 9/11. Chichester, West Sussex; Malden, MA: Wiley-Blackwell.

HueHLs, M. 2008. “Foer, Spiegelman and 9\11's Timely Traumas”. In In Literature A. Keniston and J. Quinn, Eds. After 9/11. New York: Routledge. 42-59.

JAFF, D. 2020. “The Conceptualization of Trauma in Johnathan S. Foer's Extremely Loud and Incredibly Close and Don DeLillo's Falling Man: A Cognitive Approach to 9/11 Trauma Metaphor." [MA thesis] https://www.researchgate.net/publication/342666914 The_Conceptualization_of_Trauma_in_Johnathan_S_Foer's_Extremely_Loud_and Incredibly_Close_and_Don_DeLillo's_Falling_Man_A_Cognitive_Approach_to_911_ Trauma_Metaphor. 
JAFF, D. \& Al-Jumaili, Y. 2020. “Conceptualizing Trauma in Don DeLillo’s Falling Man.” Koya University Journal of Humanities and Social Sciences, 3, 1: 123-131.

Junghaenel, D., Smyth, J. \& SANTNer, L. 2008. "Linguistic Dimensions of Psychopathology: A Quantitative Analysis.” Journal of Social and Clinical Psychology, 27, 1: 36-55.

KöveCSES, Z. 1990. Emotion Concepts. New York: Springer.

Kövecses, Z. 2000. Metaphor and Emotion: Language, Culture, and Body in Human Feeling. Cambridge: Cambridge University Press.

KöveCSES, Z. 2009. "Metaphor, Culture, and Discourse: The pressure of Coherence.” In Metaphor and Discourse, A. Musolff and J. Zinken Eds. London: Palgrave Macmillan. 11-24.

KöveCSES, Z. 2010. “Metaphor: A practical introduction.” New York: Oxford University Press.

LACAPRA, D. 2014. Writing History, Writing Trauma. Baltimore: The Johns Hopkins University Press.

LAKOFF, G. 2009. “The Neural Theory of Metaphor.” SSRN Electronic Journal, [online] 17, 38. Available at: https://terpconnect.umd.edu/ israel/lakoff-ConTheorMetaphor.pdf.

LAKoff, G. \& Johnson, M. 1980. Metaphors We Live By. Chicago: University of Chicago Press.

LEE, J., KIM, S. \& KIM, J. 2020. “The Impact of Community Disaster Trauma: A Focus on Emerging Research of PTSD and Other Mental Health Outcomes. " Chonnam Medical Journal, 56, 2: 99.

Maclean, P. \& Woody, S. 2001. Anxiety Disorders in Adults: An Evidence-based Approach to Psychological Treatment. Oxford: Oxford University Press.

Mauro, A. 2011. "The Languishing of the Falling Man: Don Delillo and Jonathan Safran Foer's Photographic History of 9/11.” MFS Modern Fiction Studies, 57, 3: 584-606.

MurraY, H. 2018. "Survivor Guilt in a Posttraumatic Stress Disorder Clinic Sample." Journal of Loss and Trauma, 223, 7: 600-607.

National Center For Ptsd. 2016. “Trauma and Relationships.” International Society for Traumatic Stress Studies. https://www.istss.org/.

Ortony, A. \& FAInsiLber, L. 1987. The Role of Metaphors in Descriptions of Emotions. aclanthology.org. Accessed 19 Aug. 2021. https://aclanthology.org/T87-1037.

Podolefsky, N. \& Finkelstein, N. 2006. "Use of analogy in learning physics: The role of representations." Physical Review Special Topics - Physics Education Research, 2, 2: 1-10.

Polisner, G. 2016. The memory of things. New York: Wednesday Books.

Pozorski, A. 2016. Falling after 9/11: Crisis in American Art and Literature. New York: Bloomsbury Academic. 
Randall, M. 2014. 9/11 And The Literature Of Terror. Edinburgh: Edinburgh University Press.

Reyes, G., Elhai, J. \& Ford, J. 2008. The Encyclopedia of Psychological Trauma. Hoboken, New Jersey: Wiley.

Rhodes, P. 2018. Towers Falling. New York: Little, Brown And Company.

Schauer, M., Neuner, F. \& Elbert, T. 2005. Narrative Exposure Therapy: A Short-term intervention for Traumatic Stress Disorders after War, Terror, or Torture. Gottingen: Hogrefe \& Huber.

Schwartz, L.s. 2005. The Writing on the Wall: A Novel. New York: Open Road.

SteEn, G. 1999. "Analyzing Metaphor in Literature: With Examples from William Wordsworth's I wandered lonely as a cloud." Poetics today: Theory and Analysis of Literature and Communication, 20, 3: 499-522.

Steen, G. 2008. "The Paradox of Metaphor: Why We Need a Three-Dimensional Model of Metaphor." Metaphor and Symbol, 23, 4: 213-241.

Stockwell, P. 2002. Cognitive Poetics: An Introduction. Abingdon, Oxon; New York, NY: Routledge.

Us Department Of Health And Human Services 2016. Treatment Improvement Protocol - trauma-informed Care in Behavioral Health Services - Tip 57. Substance Abuse and Mental Health Services Administration.

Vaile Wright, C., Collinsworth, L.L. \& Fitzgerald, L.F. 2009. "Why Did This Happen to Me? Cognitive Schema Disruption and Posttraumatic Stress Disorder in Victims of Sexual Trauma." Journal of Interpersonal Violence, 25, 10:1801-1814.

VersLuYs, K. 2009. Out of the blue: September 11 and the novel. New York, N.Y.: Columbia University Press.

WiLson, J. \& Lindy, J. 2013. Trauma, Culture, and Metaphor: Pathways of Transformation and Integration. New York; London: Routledge, Taylor and Francis. www.ldoceonline. com. (n.d.). Longman Dictionary of Contemporary English | LDOCE. Accessed 11 Jun. 2021. https://www.ldoceonline.com/.

Yu, N. 2008. "Metaphor from body and culture.” In R. W. Gibbs, Jr. Ed. The Cambridge handbook of metaphor and thought. Cambridge University Press. 247-261.

Zвikowski, L. 2011. Conceptualizing music: Cognitive Structure, Yheory, and Analysis. New York University Press. 